
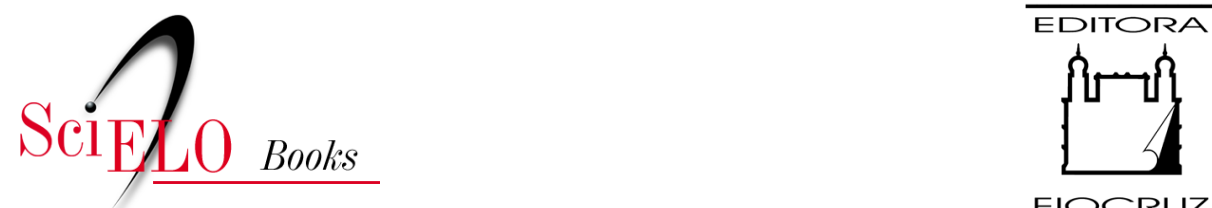

FIOCRUZ

\title{
Prefácio à segunda edição
}

\author{
Clementino Fraga
}

\section{SciELO Books / SciELO Livros / SciELO Libros}

FRAGA, C. Prefácio à segunda edição. In: Vida e Obra de Oswaldo Cruz [online]. 2nd ed. Rio de Janeiro: Editora FIOCRUZ, 2005, pp. 7-10. ISBN: 978-65-5708-099-3. https://doi.org/10.7476/9786557080993.0001.

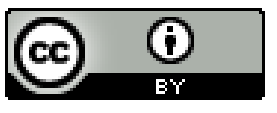

All the contents of this work, except where otherwise noted, is licensed under a Creative Commons Attribution 4.0 International license.

Todo o conteúdo deste trabalho, exceto quando houver ressalva, é publicado sob a licença Creative Commons Atribição 4.0.

Todo el contenido de esta obra, excepto donde se indique lo contrario, está bajo licencia de la licencia Creative Commons Reconocimento 4.0. 


\section{PREFÁCIO À SEGUNDA EDIÇÃO}

Suaviter in modo, forticer in re

Sẻneca

Clementino Fraga deixou, em seus arquivos pessoais, numerosa correspondên-
cia, além de outros documentos de uma vida exemplar e bem-sucedida, que se prestaria à autobiografla. Instado a escrevê-la, sempre recusou, alegando que "pobre nāo faz testamento". Entretanto, produziu ensaios biográficos sobre outros que mereceram sua admiraçăo.

o livro, lançado agora em segunda edição, por iniciativa do presidente da Fiocruz, Paulo Buss, representa derradeira homenagem de discípulo a mestre, ambos imortalizados na história da saúde pública no Brasil. Esta feliz iniciativa exprime, também, a fídelidade da instituição à memória de seu grande fundador.

Que razões teriam levado Fraga, já nos últimos anos de vida, a recordar, mais uma vez, Oswaldo Cruz? Terão prevalecido as de ordem sentimental. A capacidade de admirar e a de ser justo, de par com uma vontade poderosa, foram atributos que permitiram ao autor escolher bem os seus modelos e difundir-lhes os exemplos e as lições. Entre tais modelos, distinguiu Carneiro Ribeiro, Miguel Couto e Oswaldo Cruz.

Carneiro Ribeiro, nome nacional depois da polêmica com Rui Barbosa, foi seu professor de português no curso secundário, e moldou seu comportamento e senso de justiça. Miguel Couto, misto de competência e bondade, símbolo da medícina. Oswaldo Cruz, harmonia de qualidades, imagem de sábio. Os três foram lembrados por Fraga em sucessivas ocasiōes.

o conhecimento pessoal e a aproximação chegaram cedo. Dois anos depois de graduado, veio Fraga para o Rio de Janeiro, tentar a clínica nos subúrbios de 
Santa Cruz e Piedade. Nas manhãs livres, freqüentava a enfermaria de Miguel Couto na Santa Casa da Misericórdia, o que lhe valeu experiência e preparo para o futuro concurso na Faculdade da Bahia. No Rio, concorreu à vaga de inspetor sanitário, classificando-se em primeiro lugar, em igualdade com Vieira Romeiro, o semiólogo. Teve, então, a oportunidade de trabalhar sob as ordens de Oswaldo Cruz, em fase já avançada da campanha da febre amarela. Empolgou-o a figura do diretor, admirando-lhe a serenidade, a energia e o destemor com que enfrentava os detratores e os inimigos. Testemunhou o prestígio e o respeito geral por ele conquistados após a campanha vitoriosa, e que cresceram com sua morte aos 44 anos.

Em 1928, ocorreu novo e ameaçador surto de febre amarela, quando Fraga era diretor do Departamento Nacional de Saúde Pública, posição alcançada pela preocupação que revelou, na cátedra e no Parlamento, com a área da saúde. Creditava a consolidação de seu interesse pela saúde pública à influência do mestre, tal como Carlos Chagas, que "na recordação de Oswaldo Cruz, pautou a sua conduta pelo resto da vida".

As duas campanhas de febre amarela, além das diferenças pelo tempo decorrido e do fato de a primeira ser uma endemia e a segunda um surto epidêmico, mostraram afinidades entre os seus condutores. Oswaldo Cruz pediu demissão quando o governo nomeou um diretor sem consultá-lo. Fraga agiu da mesma forma em caso idêntico. Nos dois casos, o governo recuou. Outros tempos... Em momento difícil, Fraga substituiu, de uma só vez, quatro diretores. Oswaldo Cruz teve igual conduta com um auxiliar. Ambas as administrações sofreram intenso combate da imprensa, a que resistiram bravamente. Fraga demonstrou qualidades administrativas semelhantes às de seu chefe. Deste, disse Ezequiel Dias, discípulo da primeira hora: "nem uma frase em tom alto, jamais uma admoestação violenta; as ordens eram dadas em voz baixa; a advertência se revestia da brandura de um conselho; até o cumprimento do dever era solicitado por favor, ainda quando se tratasse do mais rude dos serventes".

No prefácio à primeira edição deste livro, Moniz de Aragão narra com minúcia um fato que concorreu para aumentar a afeição entre chefe e ex-auxiliar. Chegava à Bahia o navio Araguaia, da Mala Real Inglesa, com doentes de colera morbus. o diretor do Departamento Nacional de Saúde Pública, por indicação de Oswaldo Cruz, telegrafou a Fraga, pedindo que viesse ao Rio nesse navio, no que foi atendido, apesar das condições difíceis para sua decisão. 
Na opiniāo de seu bígrafo, o maior mérito de Oswaldo Cruz não foi o saneamento do Rio de Janeiro, com a extinçăo da febre amarela, peste e varíola, mas sim a fundação da medicina experimental no Brasil. Manguinhos é uma realidade que, vencendo todas as vicissitudes, sobrevive há mais de cem anos, com eficiência $\mathrm{e}$ brilho, representando o Brasil internacionalmente. Esse centenário foi dignamente celebrado com a exposição 'Oswaldo Cruz: o médico do Brasil'. Quem visita o Instituto ainda experimenta uma atmosfera de tradição e de recolhimento, implantada por um homem que falava pouco, era sóbrio na linguagem, fîrme na açāo, grande empreendedor, patriota extremado.

Não faltou ao homem de ciência a preparação humanista. O gosto pelas artes transparece nas numerosas cartas escritas do exterior ao seu maior amigo, Sales Guerra, médico que o indicou ao governo para a direção do Departamento Nacional de Saúde Pública. Nessas cartas, são muitos os comentários sobre exposiçōes, teatro, música, jardins.

Semelhanças entre Oswaldo Cruz e Clementino Fraga se revelaram, também, nas 'últimas vontades' de cada um. Ainda que separadas por 54 anos, nelas há coincidência de sentimentos:

Desejo com sinceridade que se näo cerque a minha morte dos atavios convencionais com que a sociedade revestiu o ato da nossa retirada do cenário da vida. Pelo respeito que voto ao pensar alheio nāo quero capitular de ridículo esses atos: julgo-os para mim dispensáveis e espero que a familia, que tanto quero, se conforme com esses inofensivos desejos que nasceram da maneira pela qual encaro a morte, fenômeno fisiológico naturalíssimo do qual nada escapa. Tão geral, tão normal, tão banal é que julgo absolutamente dispensável de frisá-la com cerimônias especiais. Por isso desejaria que se poupasse aos meus a cena de vestimenta do corpo que bem pode ser envolvido em simples lençol. Nada de convites ou comunicaçōes para enterro, nem missa de sétimo dia. Nem luto tāo pouco. Esse traz-se no coraçāo e não nas roupas. Peço encarecidamente aos meus que nāo prolonguem o natural sentimento que trará minha morte. Que se divirtam, que passeiem, que ajudem o tempo na benfazeja obra de fazer esquecer. Näo há vantagem alguma de amargurar com lágrimas prolongadas os täo curtos dias de nossa existència. Portanto, que näo usem roupas negras em nosso clima; que procurem diversóes, teatros, festas, viagens, afim de que desfaçam essa pequena nuvem que veio empanar a normalidade do viver todos os dias. É preciso que nos conformemos com os ditames da natureza.

(Oswaldo cruz) 
Desejo morrer cristāmente. Ser sepultado sem cerimônias fünebres. Nem um convite, a nem uma pessoa, ainda que aparentada ou amiga. Enterro modesto, que poderá ser custeado pela Academia Brasileira de Letras, como é de praxe, dela conseguindo a familia que dispense a meu cadáver do passeio d̀ sua sede. Sem flores, nem discursos.

Nem luto, nem restriçöes sociais de pesar, nem saudade. Nenhuma interrupçăo, ainda que efèmera, dos hábitos de vida dos filhos e dos passatempos que a amenizam. Porque a vida continua, como Deus manda em sua infinita misericórdia.

outrossim espero que a familia enlutada deixe de "cumprir o doloroso dever" de convidar para comemoraçōes religiosas. Missa e oraçōes, exclusivamente para a família.

(Clementino Fraga)

Este livro visa a lembrar alguns aspectos mais importantes da história da saúde pública no Brasil. Resume a obra de um médico que, no princípio do século XX, promoveu o saneamento do Rio de Janeiro. Mais do que isso, fundou o Instituto, marco da pesquisa científica na área biológica, consagrando o nome do seu fundador.

O Instituto atraiu cientistas e pesquisadores, nacionais e estrangei ros, assegurando-lhes condições de trabalho, orientação e apoio, como aconteceu, por exemplo, com as notáveis investigações de Chagas.

A grandeza de Manguinhos despertou a admiração de jovens profissionais. Entre eles. Clementino Fraga, vindo da Bahia e da clínica, com sólida formaçāo básica e interesse por saúde pública. Mais tarde, depois de vários ensaios sobre Oswaldo Cruz, tornou-se seu biógrafo, com a primeira ediçāo de Vida e Obra, em 1972.

A esse fervoroso discípulo pode-se aplicar o que ele escreveu a propósito de um grande clínico: "uma longa vida de clínico pode ter beleza e altitude, quando as vantagens da ciência e da arte são disciplinadas na aplicaçăo e em tudo subordinadas aos ditames da consciência profissional".

No caso presente, ciência e clínica se conjugaram para oferecer valiosa contribuição histórica. Biógrafo e biografado cumpriram, exemplarmente, a setença de Sêneca: "suave nas maneiras, forte na ação". 